\title{
Study Prevalence of Verotoxigenic E.coli Isolated from Urinary Tract Infections (UTIs) in an Iranian Children Hospital
}

\author{
Masoumeh Navidinia ${ }^{1}$, Abdollah Karimi ${ }^{1}$, Mohammad Rahbar ${ }^{2,3, *}$ Fatemeh Fallah $^{1}$, \\ Raheleh Radmanesh Ahsani ${ }^{1}$, Mohammad Ali Malekan ${ }^{1}$, Mana Hadipour Jahromi ${ }^{1}$ \\ and Zari GholineJad ${ }^{1}$
}

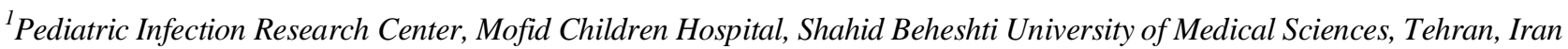 \\ ${ }^{2}$ Departments of Microbiology, Iranian Reference Health Laboratory Iran, Ministry of Health and Medical Education, \\ Tehran, Iran \\ ${ }^{3}$ Antimicrobial Resistance Center, Tehran University of Medical Sciences, Tehran, Iran
}

\begin{abstract}
Background and Objectives: Urinary tract infections (UTI) caused by enterohemorrhagic Escherichia coli (EHEC) is one of the most important diseases in infants and children. If there would not be any useful diagnosis and treatment it may be resulted in diseases such as acute renal failure, thrombocytopenia and hemolytic anemia. The aim of this study was to determine frequency of verotoxigenic E.coli isolates in urine of children with (UTIs) in Mofid children Hospital.

Methods: During one year from September 2008 to august 2009, urine specimens were taken from children who suspected to UTI admitted to Mofid Children Hospital. E.coli strains that indicated beta hemolytic on sheep blood agar, negative sorbitol fermentation on SMAC (sorbitol macconky agar) and negative motility on SIM were tested by PCR and serologic (VITEC-RPLA kit) methods for detecting toxin genes and production of toxin, respectively.

Results: Among 12572 urine specimens were taken from children admitted to Mofid hospital, we isolated 378 E.coli from urine samples which only 9 isolates were EHEC. Only five EHEC strains (55\%) which produced vtx genes, were detected by serologic and PCR methods.

Conclusion: The prevalence of urinary infections caused by EHEC strains is very significant because it causes aggravating pathologic effects. Thus we suggest rapid method for identification of this bacteria and proper treatment to Inhibition of unwanted complications.
\end{abstract}

Keywords: UTI, Enterohemorrhagic Escherichia coli( EHEC).

\section{INTRODUCTION}

Escherichia coli is the predominant facultative anaerobe of the human colonic flora. The organism typically colonizes the infant gastrointestinal tract within hours of life, and, thereafter, E. coli and the host derive mutual benefit [1].Verotoxigenic Escherichia coli (VTEC) are named for their ability to produce toxins with a cytopathic effect on Vero cells. They are also referred to as shiga toxin-producing $E$ coli (STEC) because their cytotoxins closely resemble the shiga toxin produced by Shigella dysenteriae 1. Two types of shiga toxin are produced: shiga toxin 1 (Stx1), which is most closely related to that produced by $S$. dysenteriae, and shiga toxin 2 (Stx2), which has several variants. Entero-hemorrhagic $E$ coli (EHEC) are the subgroup of VTEC organisms with demonstrated human pathogenicity. While most VTEC belong to $E$ coli serogroup O157, verotoxin production has been identified

\footnotetext{
*Address correspondence to this author at the Department of Microbiology, Research Center and Reference Health Laboratories of Iran Hafez Street, Zartoshteian Ave, Keikhosrow Shahrookh alley, No 48,. Tehran, Iran; Tel: +98 2166728112-13; Fax: +9821 66728121;

E-mail: rahbar_reflab@yahoo.com
}

in more than 200 serogroup [2]. Hemolytic uremic syndrome is the most common cause of acute renal failure in children, and the incidence of this syndrome in children is increasing worldwide [3]. E. coli $\mathrm{O} 157: \mathrm{H} 7$ is believed to cause more than 80 percent of the STEC infections that lead to hemolytic uremic syndrome [4]. Hemolytic uremic syndrome primarily occurs in children one to 10 years of age $[5,6]$ with an average annual incidence of one to three cases per 100,000 children [7] and a survival rate of nearly 95 percent. Some studies indicate that rural populations are more at risk than urban populations $[8,9]$ and the incidence is higher in warmer months of year, peaking from June to September [10].

Occurrences may be sporadic or present as an outbreak. A study conducted in the United Kingdom, in which confections intentionally were artificially contaminated with $E$. coli O157:H7 showed that the Shiga toxin-producing strains could survive for as long as one year, depending on storage conditions [11]. Three to 15 percent of persons who have STEC with diarrhea can develop hemolytic uremic syndrome [12]. Young children and older persons with altered immune response, [13] as well as persons who have been in contact with infected farm animals, are particularly vulnerable. In addition to age, risk factors associated with hemolytic uremic syndrome 
included bloody diarrhea fever, and elevated white blood cell count and C-reactive protein levels [14]. The use of antibiotics or antimotility/antidiarrheal and antimicrobial agents in early stages of diarrhea has been shown to increase the risk of hemolytic uremic syndrome because the gut is exposed to a greater number of toxins for a longer period as intestinal motility slows $[10,15]$. The pathogen is relatively tolerant to acid and can survive in fermented foods and fresh vegetable produce.

Waterborne transmission has also been reported, both from contaminated drinking-water and from recreational waters. Person-to-person contact is an important mode of transmission, particularly in institutional settings, such as day care centers, nursing homes and hospitals [16]. Reports of EHEC as a cause of diarrhea in other African countries are sporadic. In a study of childhood diarrhea in Nigeria, samples of EHEC were isolated from $5.1 \%$ of children with diarrhea [17]. A study from Japan in 1996 by Japan reported 9451 cases of EHEC infections, 1808 of which were hospitalized and 12 died; three-quarters of all these cases occurred during six major outbreaks. In the largest outbreak, in SakaiCity, 5727 people $(0.5 \%$ of the city's population) were affected, and white radish sprouts served at school lunch were the most likely food vehicle. In outbreaks reported in other areas E. coli 0157 was also isolated from the salad and seafood sauce that were served at school lunches. In 1997, E. coli 0157 was detected in wild venison and white radish sprouts associated with sporadic infections [16]. In other parts of Asia, EHEC infections have been reported. In Malaysia, E. coli 0157:H7 has been isolated from the stools of patients with diarrheal illness [18]. In a study at a Bangkok hospital in Thailand, EHEC was identified in $7 \%$ of children with bloody diarrhea in whom other enteric pathogens were not identified [19]. In the Republic of Korea, EHEC was isolated from $1.3 \%$ of children with no bloody diarrhea. An investigation into the etiology of childhood diarrhea in China, EHEC isolated from $6.8 \%$ of children with diarrhea [20]. This article will review the diarrheagenic $E$. coli strains, which include several emerging pathogens of worldwide public health importance, and will specifically focus on pathogens afflicting humans. We will particularly concentrate on the $E$. coli strain whose study has advanced most over the last decade, E. coli (EHEC). The indications for culturing for EHEC differ from those for the rest of the diarrheagenic $E$. coli categories. Routine screening test for $E$. coli in urine are most often recovered on blood agar and eosin methyleneblue agar, which selectively grow members of the Enterobacteriaceae, biochemical test such as TSI,SIM, citrate, Urease were used, and also serologic test with VTECRPLA latex agglutination kit production of toxin and multiplex PCR methods used for identifying $v t x B 1$ - and $v t x A 2$ Phenotypes.

\section{MATERIAL AND METHODS}

\section{Clinical Specimens}

Overall criteria for diagnosis UTI was growth of $\geq 10^{4}$ $\mathrm{CFU} / \mathrm{mL}$ of a urinary tract pathogen) in patients who did not have another potential source for their fever, a history of UTI, malodorous urine or hematuria, appeared "ill", abdominal or suprapubic tenderness on examination, or fever $\geq 39^{\circ} \mathrm{C}$ [25]. Patients who had received antibiotic treatment within the preceding 2 weeks, and those with known congenital anomalies of urinary tract or central nervous system-associated anomalies were excluded.

In this "prospective study" we collected 12572 urine samples from Children with UTI in Mofid children hospital Tehran, Iran /The age of patients ranged between 1-12 years old. Samples were collected in sterile plastic containers. The samples were inoculated in the Blood agar and EMB. After 24 hours of incubation at $37^{\circ} \mathrm{C}$ significant isolated microorganisms were identified by using Gram stain, catalase, oxidase, and other conventional tests. Each colonies which have $\beta$ hemolysis and Sorbitol fermentation negative on SMAC agar, suspected to EHEC so used Reverse passive Latex Agglutination Method for Detecting and Characterizing Verotoxins (Shiga Toxins) in Escherichia coli.

\section{VTEC-RPLA-SEIKEN}

A reverse passive latex agglutination was performed according to the Manufacturer's instructions (No: 230553).

\section{Collection of Samples and Preparation of Template DNA for PCR}

A total of 378 E.coli were collected over the periods from 1 October 2008 to 31 June 2009. All bacteria plated directly on both blood agar and SMAC agar (Oxoid, Wesel, Germany) and incubated overnight at $37^{\circ} \mathrm{C}$. All colonies suspended to

VTEC were diluted in $1 \mathrm{ml}$ of Nutrient broth with 15\%glycerol. The suspension was diluted 1:20 in PCR-grade $\mathrm{H}_{2} \mathrm{O}$ (Appli- Chem, Darmstadt, Germany); 1/10 was taken from this mixture for PCR with either a conventional instrument [21].

\section{Extraction of DNA and Detection of STEC Strains by (M-PCR)}

One $\mathrm{mL}$ of bacterial material was suspended in sterile water and heated at $100{ }^{\circ} \mathrm{C}$ during $10 \mathrm{~min}$ to release DNA. PCR was directly performed using consensus primers amplifying the toxin $v t x$ genes Table 1. For each PCR-positive sample, a maximum of 20 colonies obtained on the MacConkey agar plate was tested separately in order to isolate VTEC strains.

Positive vtx consensus PCR isolated colonies were subsequently identified through biochemical tests (indole production, Klieger test, $\beta$-glucuronidase activity).The $v t x 1$ and $v t x 2$ genes were finally detected in sample isolates by the Multiplex-PCR procedure. Each of the primers was used at $20 \mathrm{pM}$, with $200 \mathrm{mM}$ each deoxynucleoside triphosphates (Boehringer Mannheim, Meyher, France), 2.510X PCR buffer, $2.5 \mathrm{mM}$ $\mathrm{MgCl} 2$, and $2 \mathrm{U}$ of Taq DNA polymerase (Denmark). Then, 3 min in $95{ }^{\circ} \mathrm{C}, 35$ cycles including, denaturation for $45 \mathrm{~s}$ at 94 ${ }^{\circ} \mathrm{C}$, primer annealing for 90 s at $58{ }^{\circ} \mathrm{C}$, and extension for $90 \mathrm{~s}$ at $72{ }^{\circ} \mathrm{C}$ and, finally, $7 \mathrm{~min}$ incubation at $72{ }^{\circ} \mathrm{C}$ in a Corbett Research DNA thermal cycler (Corbett, Australia) were applied. The reaction products were then analyzed by electrophoresis on $1.2 \%$ agarose gels with $1 \%$ ethidium bromide (Fermentas, Germany). DNA from the reference strain, E. coli reference VTEC E. coli O157:H7 (ATCC; 43895), and a reagent blank, which contained all components except the template DNA(NTC), were included as positive and negative controls, respectively [22]. 


\section{RESULTS}

Fig. (1) shows the pattern and distribution of some pathogens caused UTI. E. coli with $47.2 \%$ isolate had the highest frequency followed with Klebsiella oxytoca with 147 (18.3\%) isolate. Staphylococcus epidermidis (14.2\%), Pseudomonas aeruginosa (8.2\%), Proteus mirabilis (6.4\%) and Staphylococcus aureus (4.3\%), respectively. Approximately $20.9 \%$ strains of $E$. coli which isolated from urine were $\beta$-hemolytic E. coli, $87.67 \%$ were SMAC positive and $3 \%$ were $\beta$-hemolytic and SMAC positive E. coli were ETEC.In diagram, as you see, we found only $2.3 \%$ of $E$. coli isolated from urine children with UTI was Enterohemorrhagic. (Figs. 2 and 3). The result electrophoresis Products seen on gel electrophoresis after multiplex PCR. lane M: ladder, lane 1, 2, 3: vtx-1 lane 6, 7, 8: vtx-2 (Fig. 4).

\section{DISCUSSION}

This study confirms E.coli O157:H7 as one of the major causative agent of severe UTI in children. Studies have shown that VTEC strain is commonly isolated in hemolytic colitis and hemolytic uremic syndrome belonging to serogroup O157 [23,24,26]. Following this assertion, VTEC is $v t x$ on the increase in UTI subjects with $16.7 \%$, while

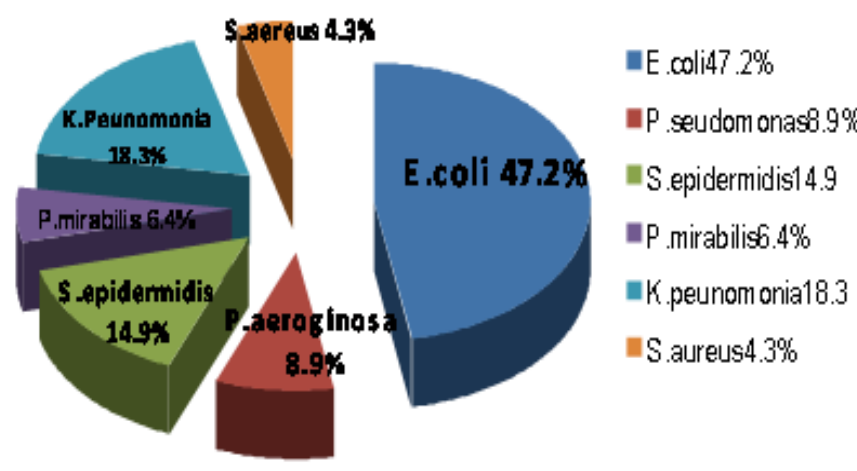

Fig. (1). The prevalence and pattern of bacteria in urine children with UTI.

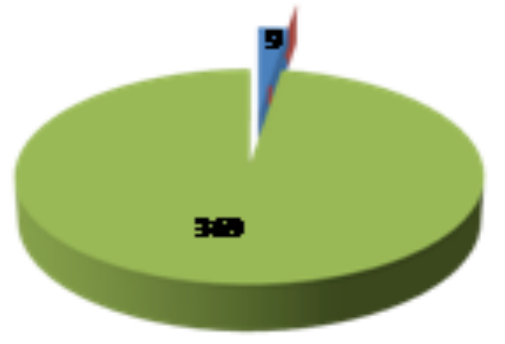

\section{BHEC 3 S \\ GHEEmS}

Fig. (2). The prevalence of Enterohemorrhagic E.coli isolated from urine children with UTI.
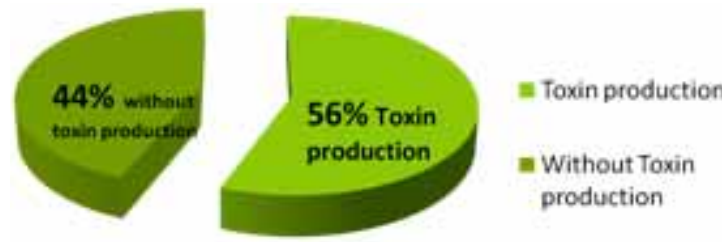

production

Fig. (3). The prevalence of Enterohemorrhagic E.coli isolated from urine children with UTI by VTEC_RPLA. chronic PID of $100 \%-1$ suggest an absolute prevalence and also gynaecological condition given an inference of $100 \%$ vtx $1 \& 2$. Then if, $v t x-1$ and $v t x-1 \& 2$ could give such an increasing prevalence, then many of these patients could as well be suffering from undiagnosed life threatening hemorrhagic colitis (HC) and hemolytic uremic syndrome [23]. Very scanty documentation of E.coli $\mathrm{O} 157: \mathrm{H} 7$ prevalence in UTI and other renal related diseases could not be obtained. Comparation of data was not possible from other part of the country due to poor documentation.

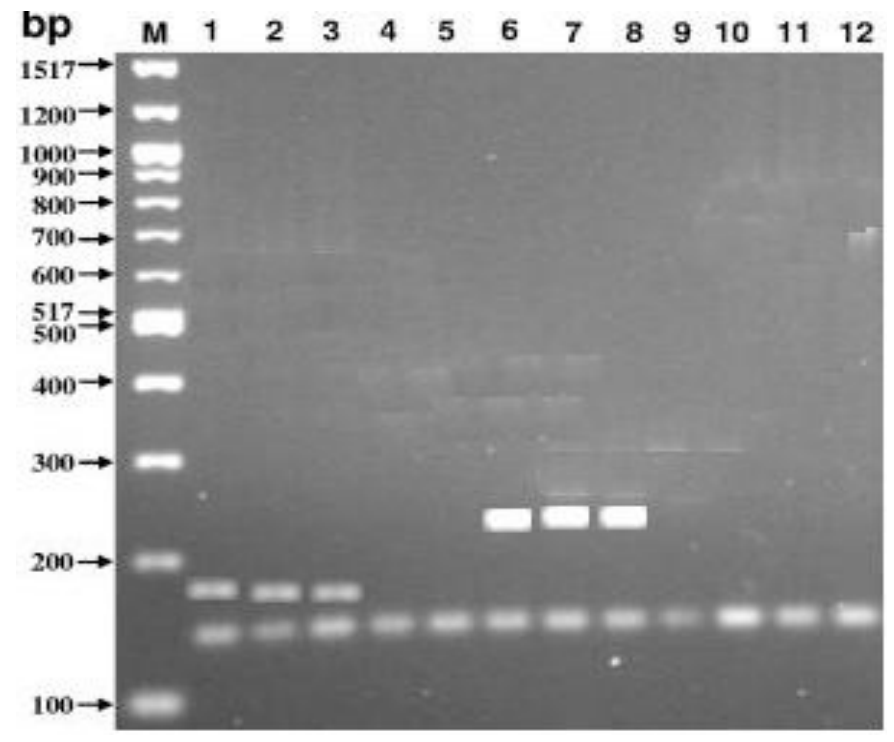

Fig. (4). The prevalence of verotoxin genes in Verotoxigenic E.coli isolated from urine children with UTI.

In our study only $2.3 \%$ of E.coli that isolated from children's urine with UTI was Enterohemorrhagic. The prevalence of EHEC in Aslani and et al., studies (Institute Pasteur of Iran, Tehran 2008 in stool) and Nazek Al-Gallas (Tunisia,2007 in stool samples) was $44.5 \%, 11.1 \%$ respectively because EHEC is more dominant in stool than urine.

Since the detection of VT represents a rational, serotype independent strategy for the diagnosis of VTEC infections, simple and reliable procedures that allow the detection of VT.

For this purpose, we evaluated the performance of a VTEC-RPLA-SEIKEN assay(An reverse passive latex agglutination Vero Toxigenic E. coli, for the detection and characterization of VTx s in E. coli culture filtrates. In this study, $44 \%$ of E.coli was non-verotoxigenic and $56 \%$ was verotoxigene. Mohamed Karmali and et al., in 1998 Evaluated a Microplate Latex Agglutination Method (Verotox-F Assay) for Detecting and Characterizing of Verotoxins (Shiga Toxins) in Escherichia coli. They examined 68 VT-positive E. coli strains and 104 VT-negative strains E. coli and conclude that the Verotox-F assay is highly sensitive and specific for the detection and characterization of VTs in culture filtrates of human E. coli isolates. The test is rapid, reliable, and easy to perform; its results are easy to interpret; and it should allow testing for VT to become more widely performed. We also used a different method of latex agglutination but the same conclusion [27].

In 1983-2002 in Atlanta, Georgia Brooks and et al., considered Non-O157 Shiga Toxin-Producing Escherichia coli 
Table 1. Oligonucleotide Primers Sequences

\begin{tabular}{|c|c|c|c|}
\hline $\begin{array}{c}\text { Amplification } \\
\text { Product Size (bp) }\end{array}$ & Reference & Sequence (5'-3') & Primer \\
\hline \hline 180 & $\begin{array}{c}\text { Paton and Paton (1998) modified } \\
\text { by Fitzmaurice J. (2003) }\end{array}$ & ATAAATCGCCATTCGTTGACTACAGAACGCCCACTGAGATCATC & VT1F \\
VT1R & $\begin{array}{c}\text { Paton and Paton (1998) modified } \\
\text { by Fitzmaurice J (2003) }\end{array}$ & GGCACTGTCTGAAACTGCTCCTCGCCAGTTATCTGACATTCTG & VT2F \\
\hline 255 & VT2R \\
\hline
\end{tabular}

Products seen on gel electrophoresis after multiplex PCR .lane M: ladder, lane 1, 2, 3: vtx-1 lane 6, 7, 8: vtx-2.

infections. They found $61 \%$ stx $1,22 \%$ st $x 2$ and $17 \%$ both stx 1 and st $x 2$ while, we had 17/3\% vtx $1,52 / 45 \% v t x 2$ and $30 / 3$ both $v t x 1$ and $v t x 2$.This significant different percent is that in our study was on O157 Shiga Toxin-Producing Escherichia coli urinary tract Infections [28]. Thus we suggest rapid method for identification of this bacteria and proper treatment to inhibition of unwanted complications.

\section{CONFLICT OF INTEREST}

None declared.

\section{ACKNOWLEDGEMENTS}

The authors would like to thank Professor Fatemeh Fallah for helpful comments and discussions. They would also like to special thanks to pediatric infection research center personnel in Mofid Children Hospital.

\section{REFERENCES}

[1] Drasar BS, Hill MJ. Human intestinal flora. London, United Kingdom: Academic Press, Ltd 1974; pp. 36-43.

[2] Nataro JP, Kaper JB. Diarrheagenic Escherichia coli. Clin Microbiol Rev 1998; 11: 142-201.

[3] Andreoli SP. The pathophysiology of the hemolytic uremic syndrome. Curr Opin Nephrol Hypertens 1999; 8: 459-64.

[4] Banatvala N, Griffin PM, Greene KD, et al. The United States national prospective hemolytic uremic syndrome study: microbiologic, serologic, clinical, and epidemiologic findings. J Infect Dis 2001; 183: 1063-70.

[5] Andreoli SP. Acute renal failure. Curr Opin Pediatr 2002; 14: 183-8.

[6] Andreoli SP. The pathophysiology of the hemolytic uremic syndrome. Curr Opin Nephrol Hypertens 1999; 8: 459-64.

[7] No authors listed. Index of suspicion. Pediatr Rev 2002; 23: 433-8.

[8] Crump JA, Sulka AC, Langer AJ, et al. An outbreak of Escherichia coli O157: $\mathrm{H} 7$ infections among visitors to a dairy farm. N Engl J Med 2002; 347: 555-60.

[9] Haack JP, Jelacic S, Besser TE, et al. Escherichia coli O157 exposure in Wyoming and Seattle: serologic evidence of rural risk. Emerg Infect Dis 2003; 9: 1226-31.

[10] Boyce TG, Swerdlow DL, Griffin PM. Escherichia coli O157: H7 and the hemolytic-uremic syndrome. N Engl J Med 1995; 333: 364-8.

[11] Baylis CL, MacPhee S, Robinson AJ, Griffiths R, Lilley K, Betts RP. Survival of Escherichia coli O157: H7, O111: H- and O26: H11 in artificially contaminated chocolate and confectionery products. Int J Food Microbiol 2004; 96: 35-48.

[12] Chang HG, Tserenpuntsag B, Kacica M, Smith PF, Morse DL. Hemolytic uremic syndrome incidence in New York. Emerg Infect Dis 2004; 10: 928-31.
[13] Westerholt S, Peiper AK, Griebel M, Volk HD, Hartung T, Oberhoffer R. Characterization of the cytokine immune response in children who have experienced an episode of typical hemolytic-uremic syndrome. Clin Diagn Lab Immunol 2003; 10: 1090-5.

[14] Kawamura N, Yamazaki T, Tamai H. Risk factors for the development of Escherichia coli O157: H7 associated with hemolytic uremic syndrome. Pediatr Int 1999; 41: 218-22.

[15] Slutsker L, Ries AA, Maloney K, Wells JG, Greene KD, Griffin PM. A nationwide case-control study of Escherichia coli O157: H7 infection in the United States. J Infect Dis 1998; 177: 962-6.

[16] WHO. Prevention and control of Enterohemorrhagic Escherichia coli (EHEC) infections. Report of a WHO Consultation Geneva, Switzerland 1997.

[17] Ogunsanya TI, Rotimi VO, Adenuga A, et al. A study of the etiological agents of childhood diarrhea in Lagos, Nigeria. J Med Microbiol 1994; 40: 10-14.

[18] Son R, Ansary A, Rusul G, Karim MIA. Isolation of verotoxinproducing Escherichia coli associated with diarrhea in Malaysia containing plasmids showing homology with biotinylated Shiga-like toxin DNA gene probes. World J Microbiol Biotechnol 1996; 12: 243-6.

[19] Brown JE, Echeverria P, Taylor DN, et al. Determination by DNA hybridization of Shiga-like-toxin-producing Escherichia coli in children with diarrhea in Thailand. J Med Microbiol. 1989; 27: 291-4.

[20] Kain KC, Barteluk RL, Kelly MT, et al. Etiology of childhood diarrhea in Beijing, China .J Clin Microbiol 1991; 29: 90-5.

[21] Pulz M, Matussek A, Tittel MMA, et al. Comparison of a shiga toxin enzyme-linked immunosorbent assay and two types of PCR for detection of shiga toxin-producing Escherichia coli in human stool. J Clin Microbiol 2003; 41: 4671-5.

[22] Mansouri-Najand L, Khalili M. Detection of shiga-like toxigenic Escherichia coli from raw milk cheeses produced in Kerman-Iran. Vet Arhiv 2007; 77(6): 515-22.

[23] Joshua EN, Israel AJ, Edigba BA. Prevalence of Escherichia coli 0157: H7 from diarrhea patients in Jos hospital, Nigeria. Journal of Food, Agric Environ 2006; 4: 20-2.

[24] Riley LW, Remis RS and Helgerson SD. Hemorrhagic colitis associated with a rare Escherichia coli serotype. N Engl J Med 1983; 308: 681-5.

[25] Martin ML, Shipman LD, Well JG, Potter ME, Hedberg K, Wachsmuth LK. Isolation of Escherichia coli 0157: H7 from dairy cattle associated with two cases of hemolytic uremic syndrome. Lancet 1986; 2: 1043.

[26] Gorelick MH, Shaw KN. Screening tests for urinary tract infection in children: a meta-analysis, Pediatrics 1999; 104: 54.

[27] Karmali MA, Petric M, Bielaszewska M. Evaluation of a microplate latex agglutination method (Verotox-F Assay) for detecting and characterizing verotoxins (Shiga Toxins) in Escherichia coli. J Clin Microbiol 1999; 37: 396-9.

[28] Brooks JT, Sowers EG, Wells JG, et al. Non-O157 Shiga ToxinProducing Escherichia coli, Infections in the United States, 19832002, J Infect Dis 2005: 192: 1422-9. 